Article

\title{
Assessing the Economic Impacts of Pesticide Regulations
}

\author{
Uwe A. Schneider ${ }^{1, *(1)}$, Livia Rasche ${ }^{1}$ and Bruce A. McCarl ${ }^{2}$ \\ 1 Research Unit Sustainability and Global Change, Department of Geosciences, Center for Earth System \\ Research and Sustainability, University of Hamburg, 20144 Hamburg, Germany; \\ livia.rasche@uni-hamburg.de \\ 2 Department of Agricultural Economics, Texas A\&M University, College Station, TX 77843-2124, USA; \\ mccarl@tamu.edu \\ * Correspondence: uwe.schneider@uni-hamburg.de; Tel.: +49-40-42838-6593
}

Received: 14 March 2018; Accepted: 29 March 2018; Published: 3 April 2018

\begin{abstract}
Economic impacts of pesticide regulations are assessed using five alternative methodologies. The regulations include crop supply-enhancing eradication programs and crop supply-decreasing pesticide bans. Alternative assessment methodologies differ regarding assumptions about market price and crop acreage adjustments. Results show that market and producer adjustments substantially impact conclusions about winners and losers from regulations, and estimated welfare effects can differ widely between the different methodologies. For small technological changes such as the hypothetical pendimethalin regulation, farm budgeting and sector modeling yield similar estimates. For more severe technological changes—like the boll weevil eradication program-simple budgeting approaches lead to a substantial bias.
\end{abstract}

Keywords: pest control; pesticide ban; insect eradication; farm income; agricultural sector analysis

\section{Introduction}

Governmental regulatory activities involving use of pesticides have stimulated numerous economic analyses regarding the consequences of pesticide withdrawal [1-3], pest eradication [4-6], integrated pest management (IPM) [7-10], pesticide reduction technologies [11,12], and genetically engineered pesticide resistance [13-15], along with many other pest-related issues. The economic approach to these analyses varies widely in scope and assumptions. Many assessments use simple budgeting implying that the pesticide action does not change total crop acres, other farm practices, or market prices [5,16-20]. Norton and Mullen review 61 farm-level budgeting-based economic evaluations of IPM programs, where the unweighted average across studies was a $2.8 \%$ reduction in costs and an $11.4 \%$ increase in yields. Farm linear programming models [21-24] have also been used and these relax the assumption of constant crop acres allowing adjustments in the farm's crop mix. Incorporating such adjustments can be important, particularly if a pesticide action decreases the profitability of a crop, causing it to be planted on a smaller area. Other studies account for commodity price effects but ignore possible acreage shifts [25,26]. Few assessments use full sectoral level analyses that allow for shifts in crop mix, crop management, total production, market prices, and patterns of product usage [27-29].

This observed diversity of methods and assumptions leads to several questions. First, why are such diverse assessment methods being used? Second, how does the methodological choice influence the results and conclusions of a study? Third, can we compare across studies impacts of a certain pesticide action, given that different methods and assumptions have been used? Fourth, to what extent do different methods change the results? Fifth, are there characteristics of the issue being 
examined that tilt the balance toward the superiority of particular methods? The objective of this paper is to examine the consequences of alternative assumptions and methodologies for the economic assessment of pesticide regulations. To provide answers to the above research questions, we apply and compare the results from and assumptions in five distinct assessment methodologies across a set of five pesticide-related policy actions. Particularly, we compute the difference in the estimated costs and benefits of the actions, as well as any differential results regarding distributional impacts-winners and losers. To minimize noise, we use the same basic data set and the same modeling system for all assessments but vary the inherent assumptions in the analysis. The five alternative evaluation methods are:

(1) farm-level budgeting, where the crop mix does not change and the crop prices remain constant;

(2) farm-level linear programming, wherein crop prices remain constant, but where farms may alter crop mix and input usage;

(3) agricultural consumers' and producers' surplus analysis, where commodity prices may change but crop acreage is fixed, and only production quantity and cost are adjusted;

(4) full cost-benefit analysis via agricultural sector modeling, where crop prices, factor prices, and crop mix may change; and

(5) national single-commodity based equilibrium welfare analysis, where price and commodity supply may change. A regionally weighted average of the yield and cost changes across regions will be used to approximate the yield and cost changes under constant acreage planting associated with a particular pesticide regulation.

\subsection{Agricultural Impacts of Pesticide Regulations}

Pesticide regulations affect farmers in two distinct ways. First, regulations that alter crop yields and/or crop production costs also alter net revenue of the associated cropping system. As a consequence, farmers are likely to reduce the area of systems that have decreased net revenues at the expense of other cropping systems with unchanged or increased net revenues. If the new pesticide regulation applies to a large region, the resulting land management adjustment may involve many farms and may substantially change aggregate commodity supply. In turn, altered supply will change market prices and the economic viability of alternative cropping systems. This possible feedback from market price adjustments on the profitability of farming systems is a second possible distinct impact of pesticide regulations. The price feedback generally acts in the opposite direction relative to the direct crop revenue impact. For example, if a pesticide regulation reduces corn yields, farmers will at first plant less corn. As the aggregate production of corn falls, the price of corn will increase. Because, higher prices compensate for yield losses, farmers will increase the area under corn and the net result will generally be smaller than the initial change. Such market adjustments generally take several years to come back into equilibrium following the implementation of the regulation.

Figure 1 shows how the different assessment methods compared in this study integrate farm level and market adjustment. Details on the individual methods are given in the next section.

\subsection{The Cases Examined}

We investigate the consequences of the alternative assessment methods for five pesticide-related actions in the context of United States agriculture. These actions include:

(1) a full implementation of the boll weevil eradication program;

(2) a ban on atrazine for corn;

(3) a ban on pendimethalin for soybeans;

(4) bans on both atrazine for corn and pendimethalin for soybeans; and

(5) all of the above 
These five actions differ substantially in their impacts on agricultural production. While the atrazine and pendimethalin bans reduce corn and soybean yields, successful boll weevil eradication increases cotton yields. Furthermore, technological adjustments such as yield and cost changes are fairly small for the pendimethalin ban, but are relatively large for the atrazine ban. These three pesticide actions are described below in more detail.

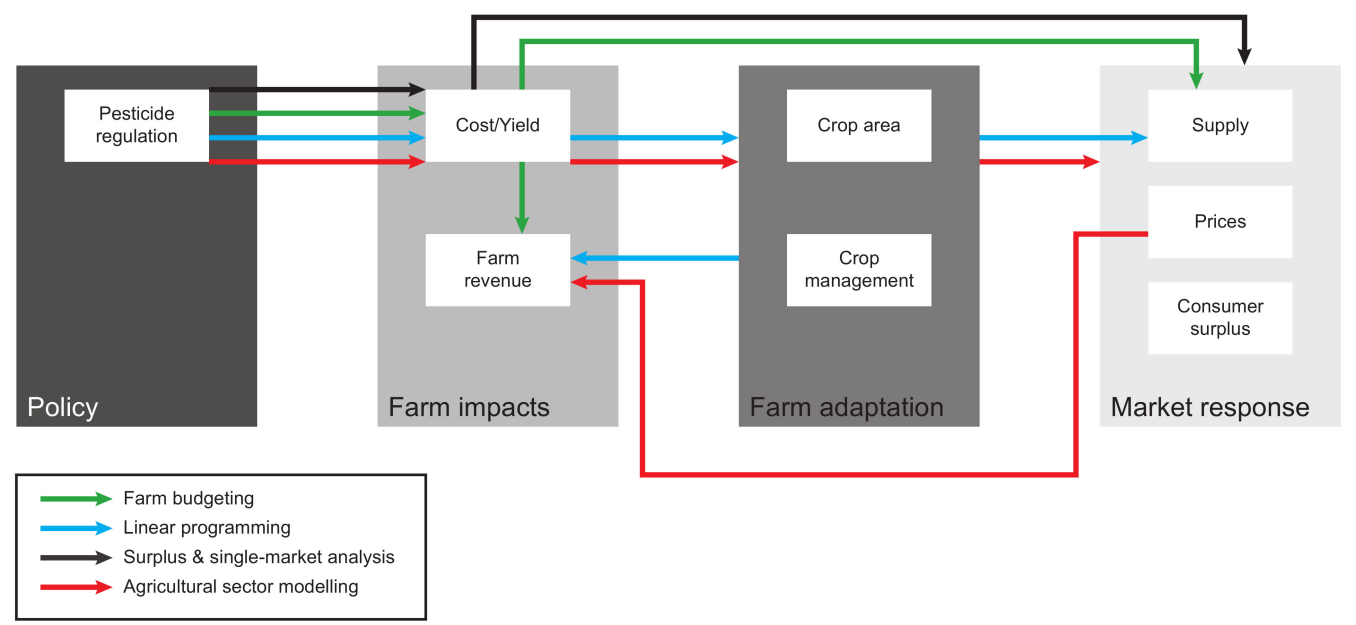

Figure 1. Scope of alternative assessment methodologies for pesticide regulations.

\subsection{Atrazine Ban on Corn}

Atrazine is a selective triazine herbicide used to control broadleaf and grassy weeds in corn, sorghum, sugarcane, and other crops. The compound is slightly to moderately toxic to humans and some animals. Trace amounts of atrazine have been detected in water samples throughout the US [30,31]. In recent years, model simulations predicted that about $5 \%$ of the total agricultural areas in the US have a greater than $10 \%$ probability of exceeding the legally permitted contaminant level [32] and thus would be subject to the ban.

In setting up and examining an atrazine ban on corn, we obtained data from United States Department of Agriculture (USDA) on the affected acreage, plus the yield and cost consequences of the ban for a number of regions in the US. Collectively, the weighted average effect across the US was a 3.2 percent decrease in yield in affected acres, and a 182 percent increase in chemical costs for use of the next best alternative, along with an estimate that 72 percent of the acres would be affected. For more details, see Table S1 in Supplementary Materials.

\subsection{Pendimethalin Ban on Soybeans}

Pendimethalin is a herbicide used to control annual grasses and certain broadleaf weeds in soybeans, potatoes, rice, cotton, tobacco, peanuts, and sunflowers. Pendimethalin is slightly toxic to humans and other mammals, moderately toxic to birds, aquatic invertebrates, algae and aquatic plants, and highly toxic to fish [33]. In setting up and examining the pendimethalin ban on soybeans, we also obtained data from the USDA giving the affected acreage along with the yield and cost effects regionally in the US. Collectively, the average effect of the ban was unchanged yields, but a 73 percent increase in chemical costs. The ban was estimated to apply to 20 percent of the soybean acreage. For more details see Table S2 in Supplementary Materials.

\subsection{National Boll Weevil Eradication}

The boll weevil eradication program was started in the late 1970s and targeted a zero population density of the cotton pest Anthonomus grandis (boll weevil). Initially, eradication programs were carried out in Virginia, North Carolina, South Carolina, Georgia, Alabama, and Florida. Later, 
the program was extended to Arkansas, Louisiana, Mississippi, Missouri, Oklahoma, Tennessee, and Texas. In 2009, eradication was finished in all states except for Texas, where the program continues on about one million acres. In this case, we will evaluate the effects assuming that only the first stage was completed, and examine the benefits of extending the program to the remaining infested states. The data on boll weevil eradication effects were obtained from the proceedings of the annual Belt-wide Cotton Conference. Collectively, the weighted average effect across the US was a 1.7 percent increase in yield on infested acres, and a 5.6 percent decrease in cost. There was an estimate that in the target states 50 percent of the acres were infested with boll weevil. For more details see Table S3 in Supplementary Materials.

\section{Materials and Methods}

To carry out the experiments and compare the results across the different methodological assumptions, we used the same basic data set and the same basic model for the analysis in all cases. In particular, we employed the Agricultural Sector and Mitigation of Greenhouse Gas Model (ASMGHG, Schneider, et al. [34] and Supplementary Materials 2) in all experiments but imposed different constraints and objective function setups to mimic the alternative assumptions. This model is a suitable tool for method comparison because in unaltered form it depicts crop mix, crop management, total production, shifts in consumption, and market price adjustments. Furthermore, by adding constraints or replacing demand/supply curve representation in the objective function it is possible to mimic the assumptions that characterize the alternative, less detailed, and less comprehensive assessment methods, i.e., by holding fixed crop mix, crop management, or market prices.

Figure 2 illustrates the standard geographic configuration of ASMGHG. Regionally restricted resources can be used for regional crop and livestock production activities. Crop products are used as livestock feed and as input for explicitly represented bioenergy and food processing technologies. Crop and livestock production in ASMGHG is represented via many different management systems (see Supplementary Materials 2). Primary and secondary agricultural products from US agriculture face domestic and foreign demand functions and processing demands as well as competition with foreign suppliers of agricultural commodities.

We used the standard configuration of ASMGHG for the price and acreage endogenous approach (method 4). In addition, we held crop acreage and management constant (fixed acreage methods 1 and 3), and altered the model from a downward sloping to an infinitively elastic, fixed price demand curve (methods 1 and 2).

There are a number of strong economic assumptions in play when each framework is used. In particular, under farm budgeting, which is done without any price or acreage adjustment, one assumes that the supply curve is perfectly elastic at a fixed cost up to a quantity where it becomes vertical or perfectly inelastic, while the demand curve is perfectly elastic (constant price). A technological change affecting a certain commodity is analyzed by shifting the supply curve of that commodity, reflecting the cost and quantity produced, but ignoring interactions with supply of other commodities. This yields a welfare change that is a function of the change in cost, the original production level and the change in quantity, and the difference between price and cost.

Under linear programming (LP), one assumes the demand curve is perfectly elastic, but the supply curve shifts up to account for increased crop management cost or decreased yields. The LP analysis allows for acreage substitution between different crops causing welfare changes due to those shifts. Thus, all competing crop commodities have to be examined.

Under a surplus analysis with shifts in the quantity supplied and cost, one assumes sloped demand but perfectly inelastic supply curves with effects such as those in the commodity market. Crop mix is assumed not to change by the implementation of a new technology or policy, and production is just altered by the change in yields, with cost also shifting. Demand adjustments include price changes reacting to the cost and yield changes but since crop acreage does not change these adjustments will only occur in markets of the commodities affected by the pesticide action. 


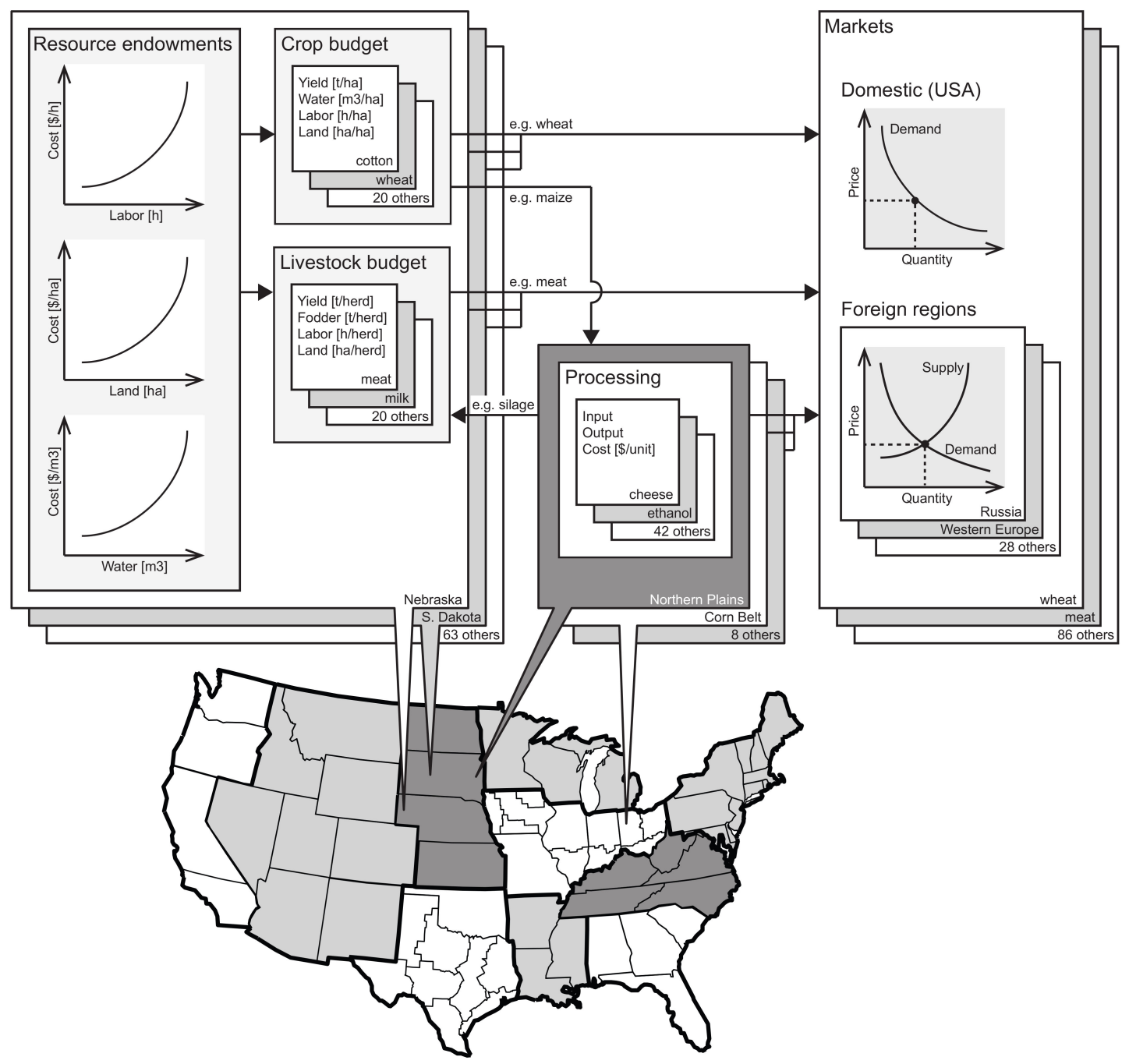

Figure 2. Structure and resolution of the US agricultural sector model.

Under a full sectoral analysis, the least restrictive set of assumptions is used. Here again production and cost per acre shift, and prices are endogenous, leading to demand adjustments which can cause crop acreage shifts. Factor use may change as well. Thus, significant welfare transfers may occur between consumers and producers. Note that here the term producer refers to the owners of agricultural resources, i.e., cropland, labor, water, and pasture and rangeland. Finally, under a single-market equilibrium analysis for just one commodity one assumes general equilibrium-type supply and demand curves as discussed in Hueth, et al. [35] to reflect market responses in terms of a single commodity. Alston, et al. [36] note that a single commodity market analysis should only be employed for a single exogenous supply or demand function displacement. As a consequence, single-market equilibrium analysis can neither be applied to multiple technological changes nor to regionally different effects of a single technological change. However, one could approximate the overall effect of a single technological change with an area-weighted average of cost and yield effects across all regions.

Furthermore, the assumptions of different assessment methodologies have important implications for the estimated welfare and income distribution effects of a pesticide action. Figure 3 illustrates these implications graphically for a pesticide action, which improves the productivity of cotton while leaving cost unchanged. Such an action would be the admission of a yield-enhancing pesticide which was previously not permitted. Under the simple budgeting approach (Figure 3a), one does not consider 
changes in anything other than in producer net revenue for affected commodities. The revenue change is simply computed as the increase in marginal net revenue (equaling the increase in yield times the current price of cotton minus the change in cost) times the current area allocated to cotton. The national net revenue change is the sum of regional revenue changes. In Figure $3 a$, the change in revenue is depicted by the upper rectangle shaded in grey.

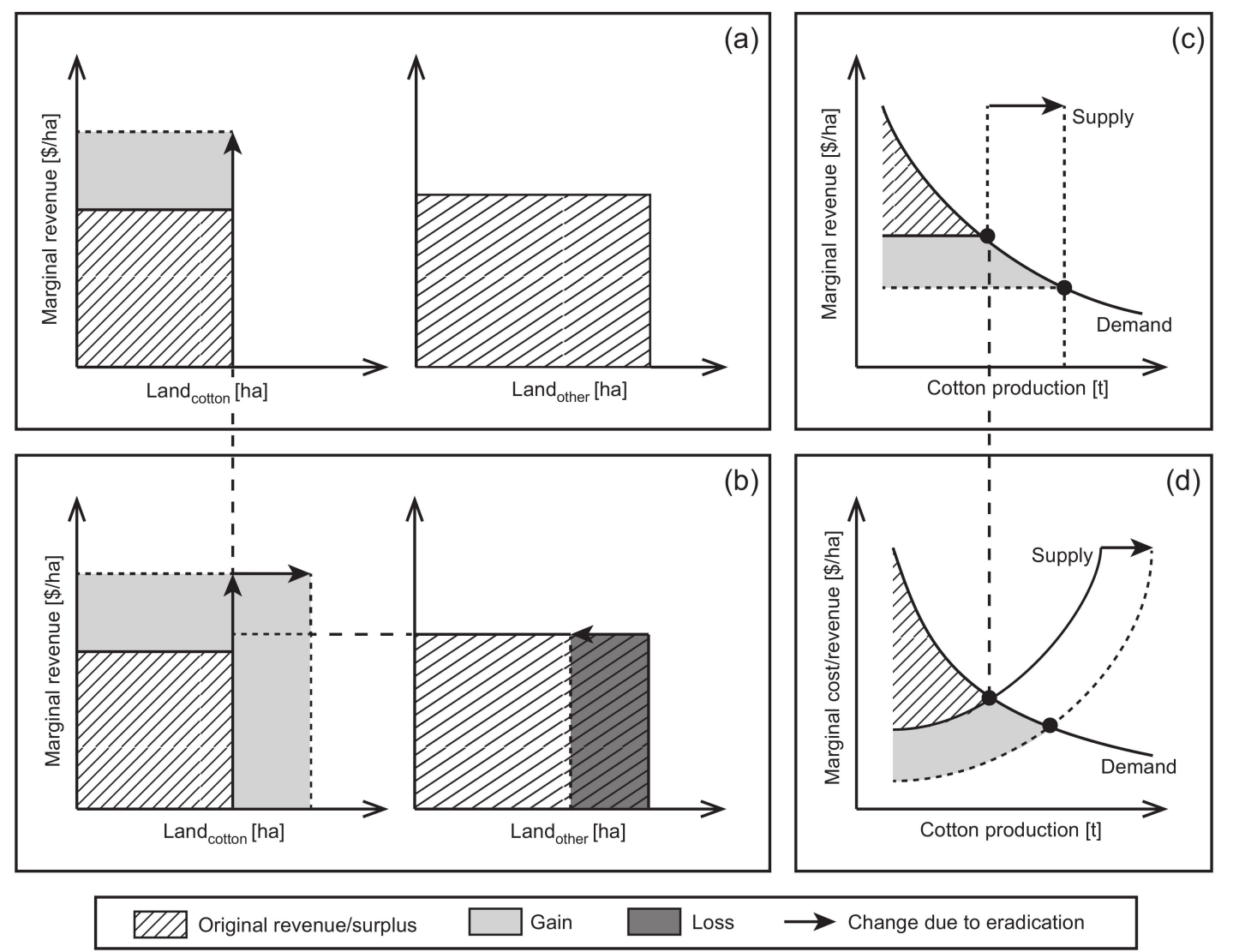

Figure 3. Differences in economic impacts: (a) farm budgeting, (b) linear programming, (c) surplus analysis, and (d) agricultural sector assessment.

In the linear programming approach (Figure 3b), one considers producer net revenue changes for the regulated and other crops but does not consider consumers' surplus. A yield-enhancing pesticide action makes the affected crop production economically more competitive. The net revenue change estimated by linear programming models includes per-hectare gains from increased profitability of improved production systems plus net gains from changes in crop mix, i.e., net gains from increasing the area under the improved crop at the expense of less profitable other crops. It should be noted that aggregate linear programming models generally need a mechanism to depict the observed heterogeneous crop mix and prevent extreme specialization. In ASMGHG, crop mix constraints are used as discussed in [37]. Because of the net benefits from crop mix adaptations, the producer gains estimated by linear programming will always be higher than their budgeting based equivalents.

The above two methods assume constant prices and can be contrasted to methods which include market adjustments via price changes. In our analysis, we distinguish three specific cases. The first case is called agricultural surplus method with inelastic (vertical) supply functions (Figure 3c). Welfare changes include consumers' and producers' surplus in all markets. This method depicts market price adjustments of a pesticide regulation but ignores producer adaptation via shifting crop mix or management. In our example, the estimated welfare change would involve an increase in consumer surplus in the commodity market of the affected crop following an increase in supply. 
Because crop mixes are assumed to be fixed, welfare transfers between commodity markets are ignored. When one looks at a full cost-benefit analysis (Figure 3d), one considers both producer and consumer effects including welfare changes that occur as a result of acreage shifts. When one analyzes a single-market equilibrium framework, one looks at consumers' and producers' surplus of the primary affected commodity, which theoretically includes welfare effects in all markets. Throughout all cases, we assume that the commodity demand functions are fixed, i.e., that the income changes generated by the pesticide program have negligible effects on agricultural commodity demand.

For the single-market equilibrium analysis (method 5), we used general equilibrium elasticities as estimated by Gardner [38]. Both in ASMGHG and Gardner's estimation, constant elasticity supply and demand relationships were applied. For complete identification of a constant elasticity function, one must also specify one price-quantity observation (identification point) in addition to the elasticity. To avoid methodological bias, we passed the general equilibrium supply and demand curves through the price and total production (equaling feed use plus exports and domestic demand less imports) of the ASMGHG base scenario. The pesticide action induced shifts of the general equilibrium supply curve was modeled by moving the identification point horizontally for a quantity change and vertically for a change in input costs.

In comparing the welfare impacts, we use two alternative measures: (i) surplus changes, and (ii) net income changes. Surplus changes are used for price-endogenous specifications with downward sloped demand, upward sloped supply, and perfect competition. Income changes to producers are reported for price-exogenous specifications (methods 1 and 2). The producer income change is calculated as total revenue change minus total cost change, where the total revenue change equals the sum of supply changes times the constant commodity price over all regions and the total cost change equals the cost change per acre times the fixed acreage summed over all regions. Consumer surplus changes are zero due to the assumed fixed price under methodologies 1 and 2 .

\section{Results}

The welfare results are summarized in Table 1. Across all model specifications, the total welfare effects (last column) are consistent in sign and fairly consistent in magnitude. However, for all applicable pesticide technology changes, the single-market equilibrium analysis leads to estimates which are at least $35 \%$ off the results obtained from the full ASMGHG version. In particular, the boll weevil eradication scenario leads only to a $45 \%$ of the change in total welfare relative to the change estimated with ASMGHG. Note that the single-market equilibrium analysis is not applicable to multiple technology changes such as the case of a combined pesticide regulation on both corn and soybeans or the case of all pesticide actions. Nevertheless, for comparative reasons we added the welfare changes obtained from the individual pesticide bans and listed the resulting number under single-market equilibrium welfare changes from the combined pesticide regulation.

Farm budgeting gives relatively close estimates to the full ASMGHG model for total market welfare changes. The two crucial assumptions made under farm budgeting offset each other to some extent. In particular, if the new technology is supply enhancing (boll weevil eradication program), the fixed crop mix assumption understates the change in total market welfare because farmers are not considered to allocate more acreage to the improved crop, i.e., cotton. The fixed price assumption, on the other hand, overstates the total market welfare change because it ignores decreasing prices from increased supply. Fixed price assumptions do substantially overestimate producers' gains under supply-enhancing pesticide programs. Alternatively, if the pesticide regulation causes a negative supply shift, budgeting overestimates producer losses. For all cases, the difference between budgeting and price with respect to acreage in endogenous ASMGHG scenarios increases with the magnitude of the program-induced supply shifts. 
Table 1. Estimates of welfare changes after technology alterations under different assumptions about market responses. For price-exogenous methods, the change refers to income changes for producers.

\begin{tabular}{|c|c|c|c|c|c|}
\hline \multirow{2}{*}{$\begin{array}{l}\text { Technology } \\
\text { Alteration }\end{array}$} & \multirow{2}{*}{ Model Specification } & \multicolumn{4}{|c|}{ Income Changes in Million US (\$) } \\
\hline & & Producers & Consumers & Foreign Countries & Total \\
\hline \multirow{5}{*}{$\begin{array}{l}\text { National boll } \\
\text { weevil eradication }\end{array}$} & ASMGHG (fully endogenous) & 17.1 & 110.5 & 11.9 & 139.5 \\
\hline & Single-market equ. & -31.1 & 93.4 & & 62.2 \\
\hline & ASMGHG (prices fixed) & 140.7 & none & none & 140.7 \\
\hline & ASMGHG (acres fixed) & 6.5 & 74.4 & 56.6 & 137.5 \\
\hline & ASMGHG (farm budgeting) & 139.1 & none & none & 139.1 \\
\hline \multirow{5}{*}{$\begin{array}{l}\text { Atrazine ban on } \\
\text { corn fields }\end{array}$} & ASMGHG (fully endogenous) & 447.0 & -847.2 & -222.9 & -623.1 \\
\hline & Single-market equ. & 87.3 & -489.0 & & -401.7 \\
\hline & ASMGHG (prices fixed) & -601.0 & none & none & -601.0 \\
\hline & ASMGHG (acres fixed) & -637.7 & -67.9 & 67.3 & -638.3 \\
\hline & ASMGHG (farm budgeting) & -637.8 & none & none & -637.8 \\
\hline \multirow{5}{*}{$\begin{array}{l}\text { Pendimethalin ban on } \\
\text { soybean fields }\end{array}$} & ASMGHG (fully endogenous) & -64.8 & 24.7 & -6.6 & -46.8 \\
\hline & Single-market equ. & -36.8 & -29.5 & & -66.3 \\
\hline & ASMGHG (prices fixed) & -54.3 & none & none & -54.3 \\
\hline & ASMGHG (acres fixed) & 37.8 & -95.3 & -11.4 & -68.9 \\
\hline & ASMGHG (farm budgeting) & -46.3 & none & none & -46.3 \\
\hline \multirow{5}{*}{$\begin{array}{l}\text { Atrazine and } \\
\text { pendimethalin ban }\end{array}$} & ASMGHG (fully endogenous) & 349.9 & -815.6 & -205.1 & -670.8 \\
\hline & Single-market equ. & 50.5 & -518.5 & & -468.0 \\
\hline & ASMGHG (prices fixed) & -670.7 & none & none & -670.7 \\
\hline & ASMGHG (acres fixed) & -683.8 & -67.9 & 67.3 & -684.3 \\
\hline & ASMGHG (farm budgeting) & -683.9 & none & none & -683.9 \\
\hline \multirow{5}{*}{$\begin{array}{l}\text { All of the above } \\
\text { pesticide actions }\end{array}$} & ASMGHG (fully endogenous) & -17.2 & -389.3 & -134.9 & -541.5 \\
\hline & Single-market equ. & 19.4 & -425.1 & & -405.8 \\
\hline & ASMGHG (prices fixed) & -599.1 & none & none & -599.1 \\
\hline & ASMGHG (acres fixed) & 1483.2 & -1579.2 & -530.3 & -626.3 \\
\hline & ASMGHG (farm budgeting) & -557.0 & none & none & -557.0 \\
\hline
\end{tabular}

Linear programming with constant prices leads to exaggerated acreage substitutions. Under regulations causing positive technological changes, i.e., the case of the boll weevil eradication program, farmers are predicted to grow a lot more of the improved crop because falling prices from increased production are ignored. The increased share of the improved crop comes at the expense of other crops, which will be grown on a smaller area. This causes a second economic bias because rising prices from reduced production of other crops are also ignored. Since both effects work in opposite directions, the economic net effects are ambiguous. Under regulations causing negative technical changes, i.e., the atrazine and pendimethalin bans, all of the above is reversed. Relative to a price endogenous assessment, fixed price-based linear programming will overestimate the acreage reduction of the hampered crop.

The directional ambiguity of the economic bias from fixed price linear programming assessments is demonstrated by the results shown in Table 1. The relatively small impact of the pendimethalin ban leads to smaller producer losses under fixed prices than under the fully endogenous ASMGHG assessment. This implies that the negative bias from ignoring higher soybean prices is smaller than the positive bias from ignoring lower prices of other crops. However, the magnitude of the bias is fairly small. For the atrazine ban, the net economic bias is not only reversed in sign but is also very large. There, a fixed price assessment leads to much larger producer losses than under the full ASMGHG assessment. In fact, the full ASMGHG assessment leads to relatively high producer gains because cost increases from the atrazine ban are more than offset by revenue increases from increased prices. The relatively large price effects after the atrazine ban causes relatively large welfare shifts from consumers to producers. Thus, while the total welfare effect of an atrazine ban is not very different between fixed price and full ASMGHG assessment, economic implications for producers differ a lot.

Agricultural surplus analysis illustrates also the significance of the acreage substitution assumption for the distribution of welfare. For all five investigated technical change cases, producers', consumers', and foreign countries' effects are substantially different under the fixed acre assumption relative to the full ASMGHG assessment. Total welfare changes, again, do not differ much from the fully endogenous ASMGHG model specification. They are, however, always lower because the 
assumptions of fixed acres take away the opportunity to reach higher total surplus levels through acreage substitution. The agricultural surplus method can be viewed as a measure of welfare changes in the primarily affected markets in a partial equilibrium setting. In contrast to the fully endogenous model, welfare shifts between commodity markets are ignored by the fixed acre assumption.

In summary, the estimated welfare effects by group differ widely between the different approaches. The assumption of constant prices (used for the farm budgeting and fixed price method) implies no change in consumers' surplus. Instead all welfare changes are attributed to producers. Comparing values in Table 1, we find that for small technological changes such as the soybean regulation, farm budgeting and sector modeling yield close estimates. The more severe a technological change is, the greater are the differences between model specifications. While for boll weevil eradication price endogenous sector modeling still yields the same direction of changes in producers' surplus, atrazine prohibition scenarios result in different signs of changes in producers' surplus between the two approaches.

The fully endogenous ASMGHG model produces significantly different estimates of welfare distribution from all other approaches. To compare ASMGHG results with single-market equilibrium analysis results, one needs to add the ASMGHG consumers' and foreign countries' surplus changes. Single-market equilibrium analysis incorporates welfare changes for foreign countries into consumer surplus changes. Yet, there are no cases in which single-market equilibrium welfare changes are similar to ASMGHG results.

All presented welfare estimates relate to changes in economic surplus measures in agricultural markets. We did not account for changes in non-agricultural sectors of the economy. Pesticide bans, however, are likely to decrease revenues in the pesticide manufacturing sector. In addition, we did not attempt to estimate the welfare changes related to policy transaction costs, and the positive or negative consequences for the environment and human health. These impacts are important but are beyond the scope of this paper.

\section{Discussion}

In this study, we examine alternative assumptions which are commonly used to assess pest and pesticide regulation-related technical changes. We compare relatively simple methods with relatively complex mathematical modeling approaches, where the latter may more closely represent reality but also require much more analytical effort. Our results show that the different methods may have relatively little influence on the total expenditure estimates for a regulation. However, we find substantial consequences for the assessment of income distribution impacts, i.e., who gains and who loses. Fixed price assessments are greatly biased if the affected commodity volume gets relatively large. Therein one would conclude that producers bear most of losses from supply decreasing actions and most of the gains from supply increasing actions. However, models with realistic, i.e., downward sloping demand functions, show that a great portion of these losses or gains are passed on to consumers. Fixed acre assessments with flexible prices also produce biased income effects because the market price adjustment is limited to one commodity market.

Single-market equilibrium welfare analysis, while theoretically consistent, did not provide comparable estimates for pesticide related technology assessments. By incorporating the market responses of the whole agricultural sector to a technological change into one single supply and demand relationship, one puts a heavy burden on econometric estimation of these general equilibrium type supply and demand functions. Thus, a methodology as used in ASMGHG or Taylor's Agricultural Simulation Model (AGSIM) seems appropriate for a comprehensive assessment of the economic impacts of pesticide regulations and pest programs. However, the usefulness of these models depends on the magnitude of the induced supply shift. Full ASMGHG results from the relatively small supply-shifting pendimethalin ban on soybeans were much closer to the farm budgeting estimates than the results from larger supply shifts caused by the atrazine ban, boll weevil eradication, and the combined regulations. 
Pesticide regulation-induced changes in income distributions can be placed in perspective with agricultural and environmental policy objectives. If pesticide restrictions lead to lower pesticide usage, crop yields are likely to decrease. Lower crop yields increase the per-unit cost of production and lead to higher commodity prices. Agricultural producers may gain or lose depending on whether the increased revenues from higher prices outweigh the increased cost of production although experience generally shows supply restrictions lead to gains because of the more inelastic nature of commodity demands. Consumers of agricultural products will always pay more. These consumer losses are caused by the reduced productivity causing higher prices and in turn welfare shifts from consumers to producers. However, consumer losses may not be too dramatic because they are shared by a large number of people. In the US, for example, fewer than 3 percent of the workers are engaged in agricultural production, implying that one producer provides food for many consumers.

In general, pesticide regulation is economically justified if the financial losses in agricultural markets are smaller than the overall gains outside agricultural commodity markets, which include environmental, human health, and other effects. Welfare shifts from consumers to producers may be considered an additional gain if these shifts increase equity within society. Furthermore, increased prices and farm income could reduce the need for governmental farm income support. For many decades, agricultural productivity improvements have caused declining commodity prices, decreasing farm income levels, and increasing farm program support.

This study has implications for the growing field of interdisciplinary research. Today, impact assessments of pesticide regulations and novel pest management regimes or more generally agricultural technological change are carried out by an increasingly diverse spectrum of scientists including, among others, natural scientists, engineers, agronomists, and economists. Personal curiosity and conviction, requirements from research funders and scientific journals, and an increasing general interest in sustainable development motivate scientists from non-economic disciplines to look at the bigger economic picture of how much their technology is worth in full application. While it is not necessary that entomologists and other agricultural scientists become highly trained economists to project the full socio-economic consequences of novel pest control options, they should be aware of that new technologies will not just fit into business as usual. New technologies will be affected by adaptation mechanisms both on the producer side (adjustments in crop mix and modifications of management intensity) and the consumer side (alterations in consumption across goods causing changes in commodity prices). If a simple assessment method is employed, resulting limitations and biases should be clearly stated to avoid misinterpretations. These qualifications are especially important when a new pest control or other technology regime is widely applicable across a large segment of commodity producers.

In interpreting our study, several limitations should be noted. First, our results are comparisons between different simulations using a mathematical model. We do not have suitable observations on the agricultural welfare impacts of the full implementation of the pesticide regulations we look at to validate our results. For example, the US boll weevil eradication program started in 1978 and is still ongoing in Texas. The comparison of farm income reports and agricultural commodity prices before and after boll weevil eradication does not yield adequate observations of welfare impacts because these data contain and mix the effects of the pesticide action with many other developments such as technical progress, new farm bills, demand changes, population growth, altered exchange rates, and many other factors. Second, all estimated economic impacts of pesticide actions are computed within a deterministic mathematical programming framework. We do not have sufficient data to explore uncertainties and confidence intervals. Thus, our results depict the most likely impacts under certain conditions and assumptions. Third, the results of model simulations with production and/or market price adjustments represent medium-term impacts assuming complete adaptation of producers and attainment of a new market equilibrium. Short-term impacts may differ because of incomplete adjustment. Finally, this study only compares welfare impacts of pesticide actions in commodity markets. A comprehensive welfare assessment should also include changes in non-market welfare 
related to the ecosystem and human health. Any methodological bias affecting how farmers respond to a pesticide action will also affect non-market welfare. For example, if farm budgeting were to be used to assess a complete pesticide ban for a certain crop, the non-market benefits of this ban would be overestimated. In reality, farmers are likely to substitute regulated crops by other crops not subject to the ban. Cases can occur where runoff of other chemical may increase, offsetting environmental gains from the ban.

\section{Conclusions}

This study compares simple and complex methods for the economic assessment of pesticide actions. Simple methods such as farm budgeting can be performed by any researcher without much training. A price-endogenous agricultural sector model, on the other hand, requires substantial investment in model development, training, and more data collection, processing, and updating. Our results show that simple methods provide reasonable estimates for the aggregate economic impact of particularly narrowly focused pesticide related actions. Simple methods can also be employed to estimate producer impacts if the pesticide action leaves the aggregate commodity supply essentially unchanged. More complex methods are needed to estimate individual welfare impacts when total supply is significantly shifted.

Supplementary Materials: The following are available online at http:/ /www.mdpi.com/2077-0472/8/4/53/s1, Table S1: Chemical cost and yield effects on atrazine treated corn fields, Table S2: Chemical cost and yield effects on pendimethalin treated soybean fields, Table S3: Chemical cost and yield effects due to of boll weevil damage.

Acknowledgments: The authors received funds from Hamburg University's Cluster of Excellence Integrated Climate System Analysis and Prediction (CliSAP) for covering the costs to publish in open access. The development of the US Agricultural Sector and Mitigation of Greenhouse Gas Model (ASMGHG) including collection and processing of diverse input data received funding various sources as documented for many years from USEPA (United States Environmental Protection Agency), USDA (United States Department of Agriculture), and USDOE (United States Department of Energy) sources. These sponsors had no role in the design of this study; in the collection, analyses, or interpretation of data; in the writing of the manuscript, and in the decision to publish the results.

Author Contributions: B.A.M. and U.A.S. conceived and designed the experiments; U.A.S. analyzed the data and performed the simulations; U.A.S. and B.A.M. wrote the first version of the paper. L.R. edited the paper. U.A.S. and L.R. designed and programmed all graphical representations.

Conflicts of Interest: The authors declare no conflict of interest.

\section{References}

1. Garcia-German, S.; Bardaji, I.; Garrido, A. New pesticides regulation: Potential economic impacts of the withdrawal of pendimethalin in horticultural crops. Span. J. Agric. Res. 2014, 12, 29-43. [CrossRef]

2. Szmedra, P. Banning 2,4-d and the phenoxy herbicides: Potential economic impact. Weed Sci. 1997, 45, 592-598.

3. Perry, J.N.; Firbank, L.G.; Champion, G.T.; Clark, S.J.; Heard, M.S.; May, M.J.; Hawes, C.; Squire, G.R.; Rothery, P.; Woiwod, I.P.; et al. Ban on triazine herbicides likely to reduce but not negate relative benefits of gmht maize cropping. Nature 2004, 428, 313-316. [CrossRef] [PubMed]

4. Hoddle, M.S.; Al-Abbad, A.H.; El-Shafie, H.A.F.; Faleiro, J.R.; Sallam, A.A.; Hoddle, C.D. Assessing the impact of areawide pheromone trapping, pesticide applications, and eradication of infested date palms for Rhynchophorus ferrugineus (coleoptera: Curculionidae) management in Al Ghowaybah, Saudi Arabia. Crop Prot. 2013, 53, 152-160. [CrossRef]

5. MacLeod, A.; Head, J.; Gaunt, A. An assessment of the potential economic impact of thrips palmi on horticulture in England and the significance of a successful eradication campaign. Crop Prot. 2004, 23, 601-610. [CrossRef]

6. Knutson, A.E.; Butler, J.; Bernal, J.; Bográn, C.; Campos, M. Impact of area-wide malathion on predatory arthropods and secondary pests in cotton during boll weevil eradication in Texas. Crop Prot. 2011, 30, 456-467. [CrossRef] 
7. Rasche, L.; Dietl, A.; Shakhramanyan, N.; Pandey, D.; Schneider, U.A. Increasing social welfare by taxing pesticide externalities in the Indian cotton sector. Pest Manag. Sci. 2016, 72, 2303-2312. [CrossRef] [PubMed]

8. Abdollahzadeh, G.; Sharifzadeh, M.S.; Damalas, C.A. Motivations for adopting biological control among Iranian rice farmers. Crop Prot. 2016, 80, 42-50. [CrossRef]

9. Ahuja, D.B.; Ahuja, U.R.; Singh, S.K.; Singh, N. Comparison of integrated pest management approaches and conventional (non-ipm) practices in late-winter-season cauliflower in Northern India. Crop Prot. 2015, 78, 232-238. [CrossRef]

10. Onstad, D.; Pan, Z.; Tang, M.; Flexner, J.L. Economics of long-term IPM for western corn rootworm. Crop Prot. 2014, 64, 60-66. [CrossRef]

11. Lamichhane, J.R.; Dachbrodt-Saaydeh, S.; Kudsk, P.; Messéan, A. Toward a reduced reliance on conventional pesticides in European agriculture. Plant Dis. 2016, 100, 10-24. [CrossRef]

12. Vasileiadis, V.P.; Otto, S.; van Dijk, W.; Urek, G.; Leskovšek, R.; Verschwele, A.; Furlan, L.; Sattin, M. On-farm evaluation of integrated weed management tools for maize production in three different agro-environments in Europe: Agronomic efficacy, herbicide use reduction, and economic sustainability. Eur. J. Agron. 2015, 63, 71-78. [CrossRef]

13. Ye, J.; Yang, Y.Y.; Xu, L.P.; Li, Y.R.; Que, Y.X. Economic impact of stem borer-resistant genetically modified sugarcane in Guangxi and Yunnan provinces of China. Sugar Tech 2016, 18, 1-9. [CrossRef]

14. Morse, S.; Bennett, R.M.; Ismael, Y. Genetically modified insect resistance in cotton: Some farm level economic impacts in India. Crop Prot. 2005, 24, 433-440. [CrossRef]

15. Vitale, J.; Boyer, T.; Uaiene, R.; Sanders, J.H. The economic impacts of introducing BT technology in smallholder cotton production systems of West Africa: A case study from Mali. AgBioForum 2007, 10, 71-84.

16. Kehlenbeck, H.; Krügener, S. Costs and benefits of plant health measures against diabrotica: Experiences and estimations for Germany. J. Appl. Entomol. 2014, 138, 222-233. [CrossRef]

17. Nault, B.A.; Speese, J., III. Major insect pests and economics of fresh-market tomato in Eastern Virginia. Crop Prot. 2002, 21, 359-366. [CrossRef]

18. Norton, G.W.; Mullen, J. Economic Evaluation of Integrated Pest Management Programs: A Literature Review; Springer: Dordrecht, The Netherlands, 1994.

19. Speese, J.; Kuhar, T.P.; Bratsch, A.D.; Nault, B.A.; Barlow, V.M.; Cordero, R.J.; Shen, Z.-X. Efficacy and economics of fresh-market BT transgenic sweet corn in Virginia. Crop Prot. 2005, 24, 57-64. [CrossRef]

20. Verghese, A.; Tandon, P.; Stonehouse, J.M. Economic evaluation of the integrated management of the oriental fruit fly Bactrocera dorsalis (diptera: Tephritidae) in Mango in India. Crop Prot. 2004, 23, 61-63. [CrossRef]

21. Acs, S.; Berentsen, P.; Huirne, R.; Van Asseldonk, M. Effect of yield and price risk on conversion from conventional to organic farming. Aust. J. Agric. Resour. Econ. 2009, 53, 393-411. [CrossRef]

22. Jacquet, F.; Butault, J.-P.; Guichard, L. An economic analysis of the possibility of reducing pesticides in French field crops. Ecol. Econ. 2011, 70, 1638-1648. [CrossRef]

23. Farquharson, R.J. A farm level evaluation of a new twinning technology in beef cattle. Rev. Mark. Agric. Econ. 1991, 59, 66-86.

24. Rovinsky, R.B.; Reichelderfer, K. Interregional Impacts of a Pesticide Ban under Alternate Farm Programs: A Linear Programming Analysis; ESCS Paper-United States Dept. of Agriculture, Economics, Statistics, and Cooperatives Service (USA): Washington, DC, USA, 1979.

25. Cembali, T.; Folwell, R.J.; Wandschneider, P.; Eastwell, K.C.; Howell, W.E. Economic implications of a virus prevention program in deciduous tree fruits in the US. Crop Prot. 2003, 22, 1149-1156. [CrossRef]

26. Myrick, S.; Norton, G.W.; Selvaraj, K.; Natarajan, K.; Muniappan, R. Economic impact of classical biological control of papaya mealybug in India. Crop Prot. 2014, 56, 82-86. [CrossRef]

27. Burton Jr, R.O.; Martin, M.A. Restrictions on herbicide use: An analysis of the economic impacts on US agriculture. North Cent. J. Agric. Econ. 1987, 9, 181-194. [CrossRef]

28. Mitchell, P.D. Market-Level assessment of the economic benefits of atrazine in the United States. Pest Manag. Sci. 2014, 70, 1684-1696. [CrossRef] [PubMed]

29. Taylor, C.R.; Penson, J.B.; Smith, E.G.; Knutson, R.D. Economic impacts of chemical use reduction on the south. J. Agric. Appl. Econ. 1991, 23, 25-26. [CrossRef]

30. Howard, P.H. Handbook of Environmental Fate and Exposure Data: For Organic Chemicals; Volume III Pesticides; CRC Press: Boca Raton, FL, USA, 1991. 
31. Goolsby, D.; Coupe, R.; Markovchick, D. Distribution of Selected Herbicides and Nitrate in the Mississippi River and Its Major Tributaries, April through June 1991; US Department of the Interior, US Geological Survey, Water Resources Division: Denver, CO, USA, 1991.

32. Stackelberg, P.E.; Barbash, J.E.; Gilliom, R.J.; Stone, W.W.; Wolock, D.M. Regression models for estimating concentrations of atrazine plus deethylatrazine in shallow groundwater in agricultural areas of the United States. J. Environ. Qual. 2012, 41, 479-494. [CrossRef] [PubMed]

33. Lewis, K.A.; Tzilivakis, J.; Warner, D.J.; Green, A. An international database for pesticide risk assessments and management. Hum. Ecol. Risk Assess. Int. J. 2016, 22, 1050-1064. [CrossRef]

34. Schneider, U.A.; McCarl, B.A.; Schmid, E. Agricultural sector analysis on greenhouse gas mitigation in US agriculture and forestry. Agric. Syst. 2007, 94, 128-140. [CrossRef]

35. Hueth, D.L.; Just, R.E.; Schmitz, A. Applied Welfare Economics and Public Policy; Prentice-Hall: Englewood Cliffs, NJ, USA, 1982.

36. Alston, J.M.; Norton, G.W.; Pardey, P.G. Science under Scarcity; CAB International: Wallingford, UK, 1995.

37. Chen, X.; Önal, H. Modeling agricultural supply response using mathematical programming and crop mixes. Am. J. Agric. Econ. 2012, 94, 674-686. [CrossRef]

38. Gardner, B.L. Causes of US farm commodity programs. J. Polit. Econ. 1987, 95, 290-310. [CrossRef]

(c) 2018 by the authors. Licensee MDPI, Basel, Switzerland. This article is an open access article distributed under the terms and conditions of the Creative Commons Attribution (CC BY) license (http:/ / creativecommons.org/licenses/by/4.0/). 